\title{
ANÁLISE EMPÍRICA DO DESEMPENHO DE UMA CÉLULA A COMBUSTÍVEL UNITÁRIA DO TIPO PEMFC
}

\author{
A. R. PONSEGGI ${ }^{1,2}$ e J. G. de M. FURTADO ${ }^{2}$ \\ ${ }^{1}$ Universidade Federal Fluminense, Departamento de Engenharia Química \\ ${ }^{2}$ Centro de Pesquisas de Energia Elétrica (Cepel), DTE \\ E-mail para contato: antonellarp@gmail.com
}

\begin{abstract}
RESUMO - Células a combustível $(\mathrm{CaC})$ são dispositivos geradores de energia que fazem o uso direto de reações eletroquímicas para a geração de potência elétrica. Neste trabalho, procurou-se analisar o comportamento de uma $\mathrm{CaC}$ unitária de membrana polimérica a partir das curvas de polarização e de potência geradas experimentalmente. $\mathrm{O}$ objetivo foi avaliar de que forma as variações de diversos parâmetros influenciaram o desempenho da $\mathrm{CaC}$ e em que condições a mesma apresentou o melhor comportamento, determinando-se o conjunto de condições de operação e características constitutivas que gerariam uma $\mathrm{CaC}$ mais eficiente. Concluiu-se que as condições mais favoráveis foram pressão igual a $1,1 \mathrm{bar}$, temperatura entre 60 e $70^{\circ} \mathrm{C}$, espessura da membrana de $51 \mu \mathrm{m}$ e quantidade de catalisador de $0,4 \mathrm{mg} / \mathrm{cm}^{2}$ no anodo e $0,6 \mathrm{mg} / \mathrm{cm}^{2}$ no catodo. Sob as condições estudadas, o regime de vazão dos reagentes não afetou o desempenho da $\mathrm{CaC}$.
\end{abstract}

\section{INTRODUÇÃO}

Células ou pilhas a combustível $(\mathrm{CaC})$ são células eletroquímicas do tipo galvânicas, em que semi-reações ocorrem espontaneamente e transformam diretamente energia química em energia elétrica (Larminie e Dicks, 2003). Seus eletrodos estão separados por uma membrana eletrolítica, isolante para corrente eletrônica, permitindo apenas a passagem de íons entre o anodo e o catodo, o que obriga a corrente eletrônica gerada a passar pelo circuito externo à $\mathrm{CaC}$, fornecendo a energia necessária ao sistema alimentado (carga). As semi-reações que ocorrem no sistema em questão estão representadas nas Equações 1 a 3.

Este trabalho refere-se à análise dos resultados de experimentos feitos com uma $\mathrm{CaC}$ unitária de membrana polimérica (PEMFC, do inglês Proton Exchange Membrane Fuel Cell) do tipo $\mathrm{Nafion}^{\circledR}$, como ilustrada na Figura 1(a), condutora de prótons (hidratados, $\mathrm{H}_{3} \mathrm{O}^{+}$) impregnada com catalisador (Platina) e operação em baixas temperaturas e pressões, devido à natureza termomecânica frágil da membrana (Barbir, 2005). Variou-se o regime de vazão e pressão dos gases reagentes $\left(\mathrm{H}_{2}\right.$ e $\mathrm{O}_{2}$, em condições saturadas de umidificação), a temperatura de operação, a espessura da membrana e a quantidade de catalisador nos eletrodos. A coleta de dados deu-se variando a corrente elétrica (i) solicitada (mediante variação da carga resistiva imposta) e observando a variação de potencial eletroquímico (U) resultante, obtendose assim as curvas de polarização e potência (P, Equação 4) produzidas e verificando-se a influência sobre o desempenho da PEMFC e as condições mais favoráveis de operação para obtenção de maiores eficiências.

$$
2 \mathrm{H}_{2} \rightarrow 4 H^{+}+4 e^{-} \quad \text { (anodo) }
$$




$$
\begin{aligned}
& \mathrm{O}_{2}+4 e^{-} \rightarrow 2 \mathrm{O}^{2-} \quad \text { (catodo) } \\
& 4 \mathrm{H}^{+}+2 \mathrm{O}^{2-} \rightarrow 2 \mathrm{H}_{2} \mathrm{O} \text { (catodo) } \\
& \mathrm{P}=\mathrm{U} * i
\end{aligned}
$$

Figura 1 - (a) Esquema explicativo de uma PEMFC unitária. (b) bancada de testes e ensaios de $\mathrm{CaC}$ de baixa potência. (c) PEMFC unitária e seus componentes principais - (d) MEA e (e) papel difusor de carbono - utilizados neste trabalho.
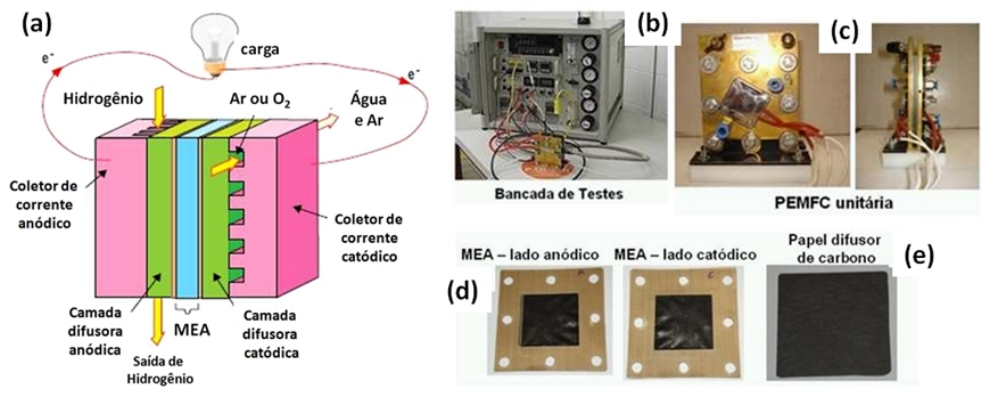

Nota-se na figura 1(a) (Thomas et al., 1999), o detalhe dos eletrodos em conjunto com a membrana (MEA) e as placas bipolares (em rosa no esquema), que transportam os gases e auxiliam na condução da corrente elétrica (coletores de corrente).

\section{RESULTADOS E DISCUSSÃO}

Foi utilizada uma PEMFC de bancada fornecida pela empresa Electrocell, como ilustrado na Figura 1(b)-(c). O MEA, Figura 1(d), foi disposto entre folhas (camadas difusoras de gases) de papel carbono, Figura $1(\mathrm{e}), \mathrm{com} 25 \mathrm{~cm}^{2}$ de área (mesma área efetiva da $\mathrm{CaC}$ ) e $\mathrm{o}$ catalisador consistia em platina dispersa sobre carbono nas concentrações estudadas. Por sua vez, o MEA foi disposto entre placas bipolares de grafita e placas metálicas fechavam o conjunto sobre uma base isolante (Figura 1(c)). A membrana polimérica utilizada foi da classe Nafion ${ }^{\circledR}$ e os ensaios foram feitos com corrente entre 0 e $23 \mathrm{~A}\left(0\right.$ a $\left.920 \mathrm{~mA} / \mathrm{cm}^{2}\right)$, e resultados em valores médios de potencial em operação estável. Nos ensaios, foi feita variação de um dos parâmetros (ou dois, quando especificado), mantendo fixos os demais, como na tabela 1 .

Tabela 1 - Condições gerais de operação da PEMFC

\begin{tabular}{ccccccc}
\hline Pt no anodo & Pt no catodo & $\mathrm{P}($ bar $)$ & $\mathrm{L}(\mu \mathrm{m})$ & $\mathrm{T}_{\mathrm{CaC}}\left({ }^{\circ} \mathrm{C}\right)$ & $\mathrm{H}_{2}(\mathrm{~L} / \mathrm{min})$ & $\mathrm{O}_{2}(\mathrm{~L} / \mathrm{min})$ \\
\hline $0,4 \mathrm{mg} / \mathrm{cm}^{2}$ & $0,6 \mathrm{mg} / \mathrm{cm}^{2}$ & 0,5 & 60 & 60 & 0,662 & 0,995 \\
\hline
\end{tabular}

\subsection{Série 1 - Variação da vazão dos reagentes $\left(\mathrm{H}_{2}\right.$ e $\left.\mathrm{O}_{2}\right)$}

Figura 2 - Variação das vazões de $\mathrm{H}_{2}$ e $\mathrm{O}_{2}$ (L/min, independente de i).

3 e $4-$

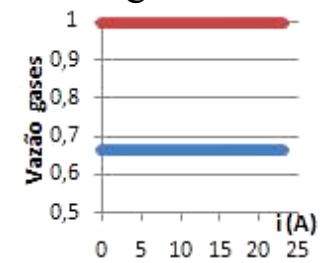

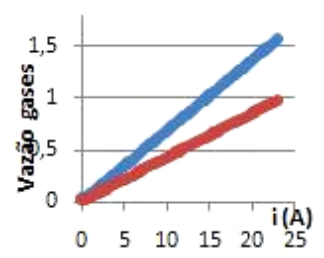
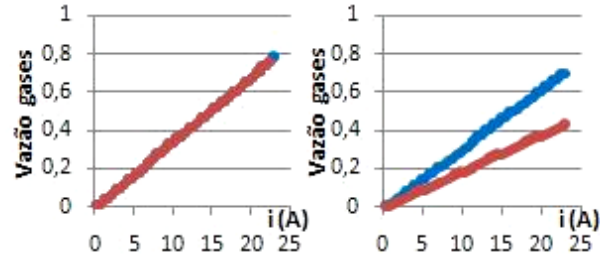

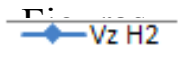

$-\mathrm{V} / \mathrm{V} \mathrm{O} 2$ 
de polarização e potência com as diferentes vazões dos gases.
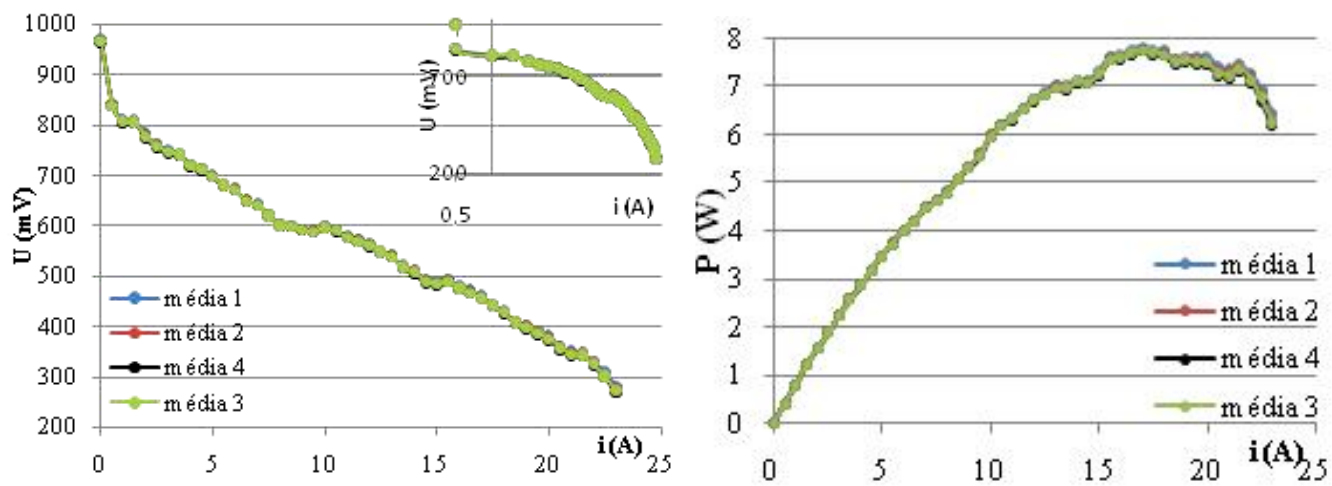

Apesar da visível diferença entre as vazões utilizadas, as curvas das figuras 3 e 4 estão praticamente sobrepostas umas às outras, indicando uma insensibilidade da PEMFC em relação à vazão nas condições estudadas. Possivelmente o experimento foi realizado sob condições "ótimas" de operação, com todas as vazões acima de um nível mínimo para evitar limitação das reações quanto ao abastecimento de reagentes. Assim, a não influência das flutuações nas vazões nos permite buscar regimes de vazão mais econômicos, justamente o que se procura na prática, alimentar o sistema com uma vazão mínima necessária para se manter a potência desejada (Barbir, 2005). Como não foi observada nenhuma influência das vazões no sistema, estas foram mantidas fixas nos demais experimentos.

\subsection{Série 2 - Variação da temperatura de 30 a $80^{\circ} \mathrm{C}$}

Figuras $5 \mathrm{a}$ e $5 \mathrm{~b}$ - Curvas de polarização com as diferentes Temperaturas.
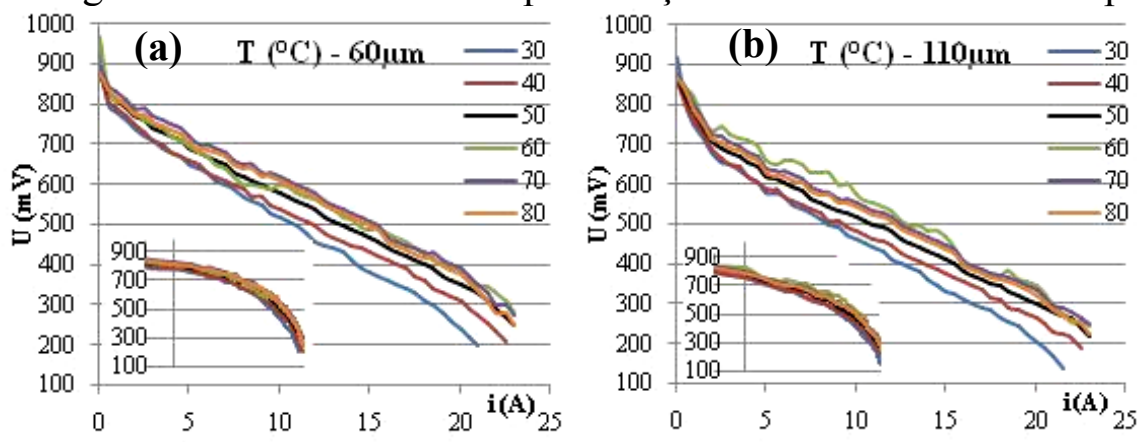

$\mathrm{O}$ aumento do potencial gerado com o aumento da temperatura do sistema representa menores perdas energéticas em maiores temperaturas. Porém, ao aproximar-se de $60^{\circ} \mathrm{C}$, essa tendência diminui e até se reverte ligeiramente. As curvas de $60^{\circ} \mathrm{C}$ apresentam os maiores potenciais, e as de 70 e $80^{\circ} \mathrm{C}$ situam-se entre as de 50 e $60^{\circ} \mathrm{C}$. Isso pode ser explicado pelo fato da reação ser favorecida cineticamente por temperaturas elevadas (processo catalítico com a platina), enquanto termo-dinamicamente favorecida por baixas temperaturas, devido à limitação exotérmica, mesmo ocorrendo indiretamente com a geração de corrente elétrica (Chun et al., 2011). Portanto, a PEMFC mostrou melhor desempenho entre 60 e $70^{\circ} \mathrm{C}$ (Figuras 5 e 6). Pode-se considerar que a $70^{\circ} \mathrm{C}$ as características do eletrólito (Nafion ${ }^{\circledR}$ ) começam a decair e que a operação prolongada provocaria uma redução mais acentuada da eficiência da PEMFC, em função da degradação do eletrólito (Barbir, 2005). Em 30 e $40^{\circ} \mathrm{C}$, fica evidenciado que a $\mathrm{CaC}$ está operando em condições térmicas incipientes, uma vez que os potenciais e potências são significativamente inferiores aos das demais temperaturas. 
Comparando-se os resultados das membranas Nafion ${ }^{\circledR}$ de 60 (vermelho) e $110 \mu \mathrm{m}$ (azul) nas figuras 7 e 8 , também se pode dizer que membranas mais finas resultam em maiores potenciais e potências, já que a resistência à corrente iônica será menor.

Figuras 7 e 8 - Curvas de polarização e potência com $\Delta \mathrm{T}$ e espessuras da membrana.
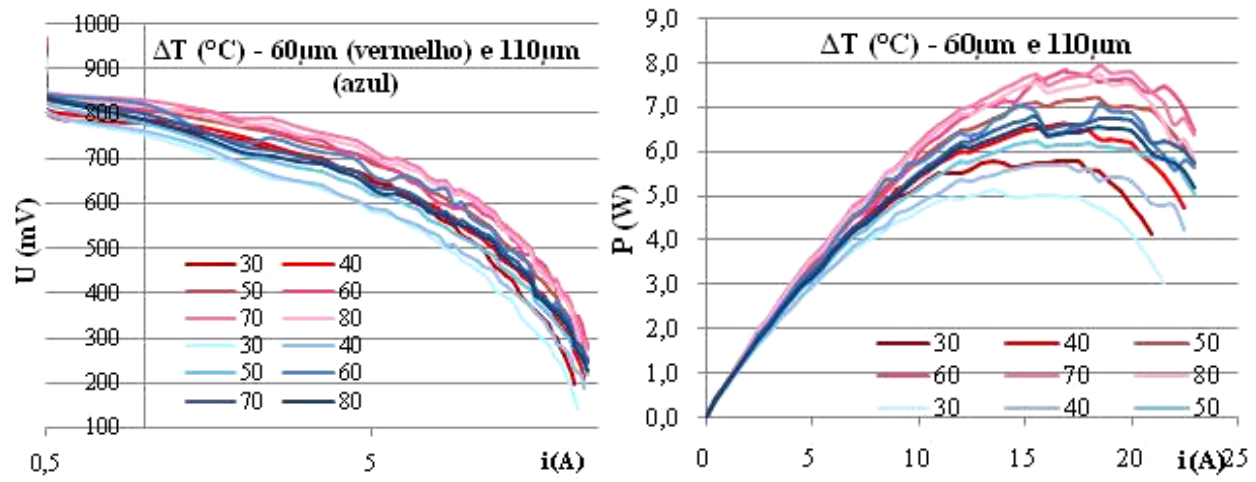

\subsection{Série 3 - Variação das espessuras da membrana}

Como esperado, as menores espessuras permitiram maiores potenciais gerados devido à menor resistência à corrente iônica. Também houve uniformidade nas curvas, sem grandes desvios, curvas se cruzando, grandes picos, etc. (visto figura 9), o que deixa clara a influência da polarização ôhmica sobre toda a faixa de potência avaliada (Barbir, 2005). Os casos extremos apresentaram maior diferença em relação às demais curvas, sendo que a de $51 \mu \mathrm{m}$ resultou em um potencial bem maior que as demais.

Figuras 9 e 10 - Curvas de polarização e potência com as diferentes espessuras.
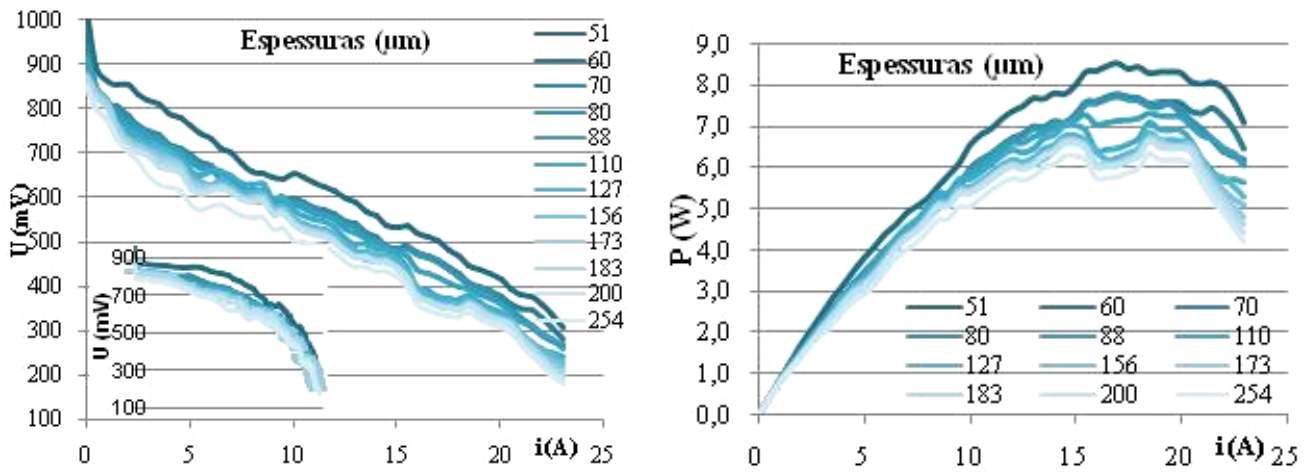

\subsection{Série 4 - Variação de Pressão}

As curvas de polarização da figura 11 mostram a pequena influência da pressão sobre o desempenho da $\mathrm{CaC}$ estudada, já que esta foi alterada significativamente e isto gerou apenas uma leve modificação nos potenciais. Ainda assim, as maiores pressões resultaram em maiores potenciais, efeito da maior quantidade de reagentes passando para uma mesma vazão volumétrica, e maior contato entre os gases e a platina (catalisador). Em um empilhamento, o efeito das pressões seria ampliado e poderia causar expressiva diferença no desempenho final da PEMFC, especialmente a altas densidades de corrente (Figura 12). A pressão de 1,1 bar $(\approx 1 \mathrm{~atm})$ é bastante vantajosa por não incluir a necessidade de gastos energéticos com equipamentos para alteração da pressão (ex. compressores).

Figuras 11 e 12 - Curvas de polarização e potência nas diferentes pressões (bar). 

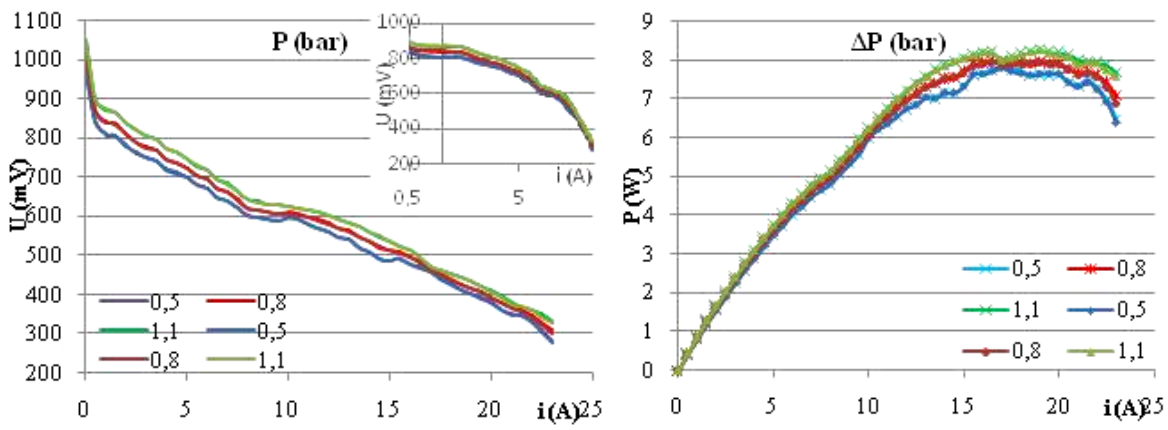

A baixa resistência mecânica das membranas provoca a necessidade de menor pressão das correntes gasosas, mas é principalmente a diferença de pressão anodo-catodo que prejudica seu desempenho, pois poderia provocar uma ruptura após algum tempo de operação. É preciso uma cuidadosa análise da membrana a ser utilizada.

\subsection{Série 5 - Variação das cargas de catalisador (Pt) e vazões}

Tabela 2 - Conteúdo de Platina nas membranas da PEMFC na série 5

\begin{tabular}{cccc}
\hline $\mathrm{Pt}$ & Catodo $-\mathrm{O}_{2}$ & Anodo $-\mathrm{H}_{2}$ & Razão $\mathrm{Pt}\left(\mathrm{O}_{2} / \mathrm{H}_{2}\right)$ \\
\hline 1 & $0,6 \mathrm{mg} / \mathrm{cm}^{2}$ & $0,4 \mathrm{mg} / \mathrm{cm}^{2}$ & 1,50 \\
2 & $0,6 \mathrm{mg} / \mathrm{cm}^{2}$ & $0,3 \mathrm{mg} / \mathrm{cm}^{2}$ & 2,00 \\
3 & $0,4 \mathrm{mg} / \mathrm{cm}^{2}$ & $0,6 \mathrm{mg} / \mathrm{cm}^{2}$ & 0,67 \\
4 & $0,5 \mathrm{mg} / \mathrm{cm}^{2}$ & $0,5 \mathrm{mg} / \mathrm{cm}^{2}$ & 1,00 \\
\hline
\end{tabular}

Figuras 13a e 13b - Curvas de polarização com diferentes cargas de catalisador.
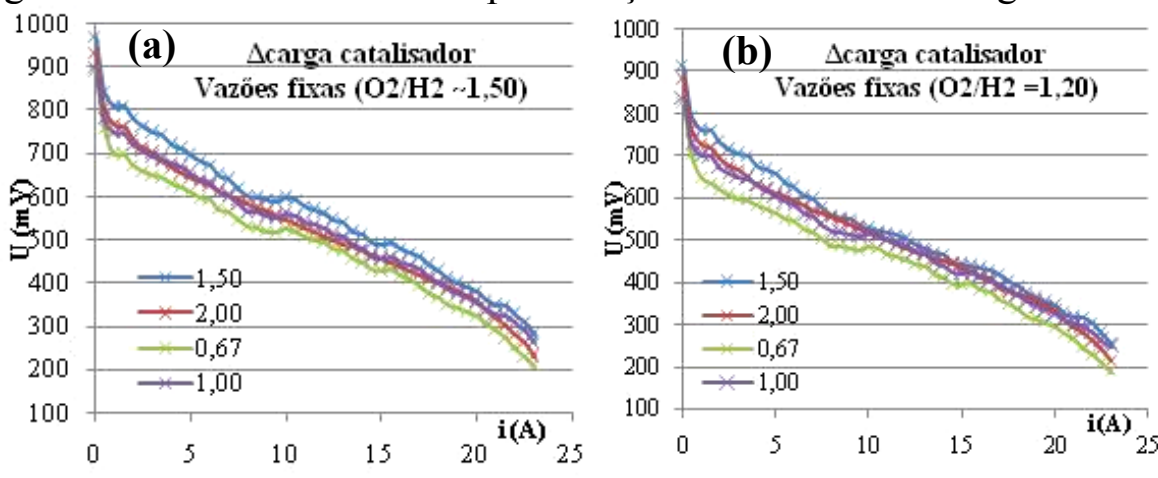

Os casos 1-4 da tabela 2 foram submetidos ao regime "A" $\left(0,995 \mathrm{~L} / \mathrm{min} \mathrm{O}_{2}\right.$ e 0,662 $\left.\mathrm{L} / \mathrm{min} \mathrm{H}_{2}\right)$ com razão $\mathrm{O}_{2} / \mathrm{H}_{2} \sim 1,5$, e "B" $\left(0,6 \mathrm{~L} / \mathrm{min} \mathrm{O}_{2}\right.$ e $\left.0,5 \mathrm{~L} / \mathrm{min}\right)$, razão $\mathrm{O}_{2} / \mathrm{H}_{2}=1,2$. Os gráficos da figura 13 mostram um melhor desempenho da curva 1, seguida das curvas 2 e 4 muito próximas entre si, e por último a curva 3. Vê-se que a maior quantidade de catalisador no catodo é favorável à PEMFC, explicitando o fato da redução do $\mathrm{O}_{2}$ ter densidade de troca de corrente muito menor que a oxidação do $\mathrm{H}_{2}$, por ser mais lenta (limitante) (Benz et al., 2009). Necessita-se tanto de maior vazão de $\mathrm{O}_{2}$ quanto de maior quantidade de catalisador no catodo, a fim de atender à demanda de reação do $\mathrm{H}_{2}$ no anodo. Os valores quantitativos de $\mathrm{Pt}$ são de extrema importância, vide comparação das curvas 1 e 2 pela figura 13 e tabela 2 . Comparando os regimes A (vermelho) e B (verde) nas figuras 14 e 15, o regime A, com maior razão $\mathrm{O}_{2} / \mathrm{H}_{2}$, apresentou melhor desempenho de um modo geral. A curva 1 do regime $\mathrm{A}$ é a melhor opção para uma alta eficiência. A curva 1 do regime B aproxima-se das curvas 2 e 4 do regime A e mostra que condições específicas de operação podem afetar significativamente o desempenho final da $\mathrm{CaC}$ e possibilitam a superação de limitações do sistema. 
Figuras 14 e 15 - Comparação de desempenho entre os regimes A e B.
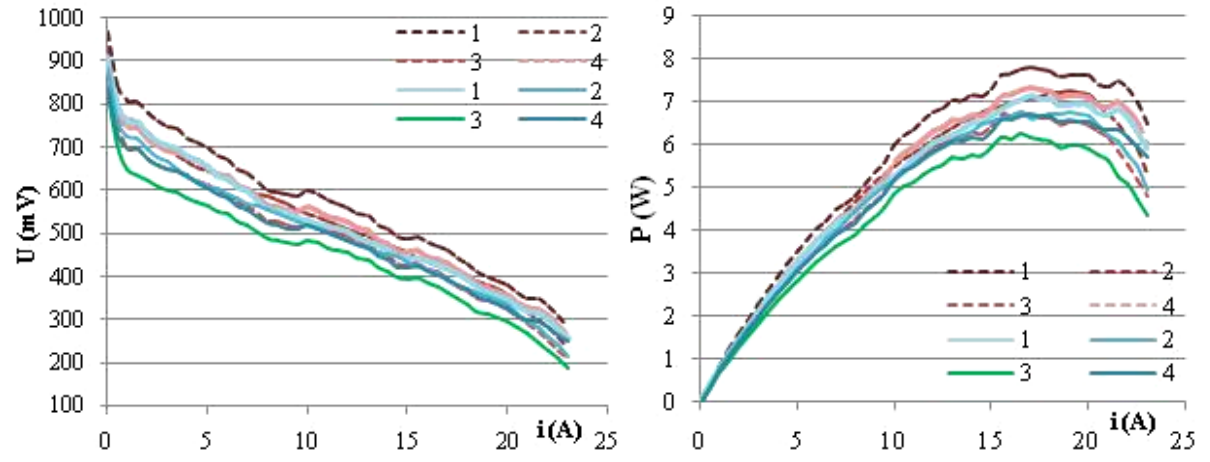

\section{CONCLUSÃO}

A partir da análise efetuada, tendo-se como premissa a busca por sistemas e condições de operação com maior eficiência e com base nos dados experimentais, indica-se o melhor conjunto de parâmetros para PEMFC unitária avaliada: Vazões dos reagentes de $0,995 \mathrm{~L} / \mathrm{min}$ $\mathrm{O}_{2}$ e $0,662 \mathrm{~L} / \mathrm{min} \mathrm{H}_{2}$, temperatura de $60^{\circ} \mathrm{C}$, espessura da membrana de $51 \mu \mathrm{m}$, pressão de 1,1 bar e cargas de catalisador de $0,6 \mathrm{mg} / \mathrm{cm}^{2} \mathrm{Pt}$ no catodo e $0,4 \mathrm{mg} / \mathrm{cm}^{2} \mathrm{Pt}$ no anodo. Em todos os casos analisados, destacou-se uma faixa de densidade de corrente que resultou em uma região de potência máxima $(7-8 \mathrm{~W})$ ao redor de $15-20 \mathrm{~A}\left(0,2-0,8 \mathrm{~A} / \mathrm{cm}^{2}\right)$. Acima desses valores, a aumento das perdas de energia superam os da potência gerada, fazendo com que esta diminua, assim como a eficiência da $\mathrm{CaC}$. Foram escolhidas as vazões fixas acima por não necessitarem de um sistema de controle da variação das mesmas durante ao longo do seu funcionamento, além da maior razão $\mathrm{O}_{2} / \mathrm{H}_{2}$, que favorece a cinética do sistema pela quantidade de catalisador presente no catodo. As cargas de catalisador escolhidas não foram as de maior razão de platina catodo/anodo, e sim as de segunda maior $(\sim 1,5)$, pois favorecem a cinética do sistema e respeitam suas limitações quantitativas. A membrana de $51 \mu \mathrm{m}$ foi a mais eficiente dentre as testadas, no entanto, pela natureza frágil de tais membranas, pode ser que, esta não seja a mais adequada.

\section{REFERÊNCIAS}

BARBIR, F. PEM Fuel Cells: Theory and Practice. Elsevier Academic Press, 2005.

BENZ, U., BUSCHE, D., LUTTERBECK, D. APPLICATIONS - STATIONARY | Uninterruptible and Back-up Power: Fuel Cells. Encyclopedia of Electrochemical Power Sources, p. 135-145, 2009.

CHUN, J. H., PARK, K. T., JO, D. H., KIM, S. G., KIM, S. H. Numerical modeling and experimental study of the influence of GDL properties on performance in a PEMFC. International Journal of Hydrogen Energy, v.36, n.2, p.1837-1845, 2011.

HONGSIRIKARN, K., MO, X., LIU, Z., GOODWIN Jr, J. G. Prediction of the effective conductivity of Nafion in the catalyst layer of a proton exchange membrane fuel cell. Journal of Power Sources, v.195, n.17, p. 5493-5500, 2010.

LARMINIE, J., DICKS, A. Fuel Cell Systems Explained, John Wiley \& Sons, UK, 2003.

THOMAS, S.; ZALBOWITZ, M. Fuel Cells, Green Power. Los Alamos National Laboratory, New Mexico, 1999. 